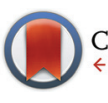

CrossMark \&lick for updates

Cite this: Polym. Chem., 2015, 6 , 6409

Received 22nd June 2015

Accepted 22nd July 2015

DOI: $10.1039 / c 5 p y 00962 f$

www.rsc.org/polymers

\title{
Designed enzymatically degradable amphiphilic conetworks by radical ring-opening polymerization $\uparrow$
}

\author{
Yinfeng Shi, Holger Schmalz and Seema Agarwal*
}

\begin{abstract}
A new route for the preparation of enzymatically degradable amphiphilic conetworks (APCNs) based on unsaturated polyesters by radical ring-opening copolymerization of vinylcyclopropane (VCP) with cyclic ketene acetal (CKA) is presented in this article. In the first step, the unsaturated biodegradable polyesters with random distribution of cross-linkable double bonds and degradable ester units were prepared by radical ring-opening copolymerization of VCP and CKA such as 2-methylene-4-phenyl-1,3-dioxolane (MPDO). Very similar reactivity ratios $\left(r_{\mathrm{VCP}}=0.23 \pm 0.08\right.$ and $\left.r_{\mathrm{MPDO}}=0.18 \pm 0.02\right)$, unimodal gel permeation chromatography (GPC) curves and 2D NMR technique (heteronuclear multiple bond correlation, HMBC) showed the formation of random copolymers with unsaturation and ester units. The unsaturated units were used for cross-linking by radical polymerization with a hydrophilic macromonomer (oligo (ethylene glycol) methacrylate, OEGMA) in a second step for the formation of enzymatically degradable amphiphilic conetworks (APCNs). Enzymatic degradability was studied using Lipase from Pseudomonas cepacia. Due to the hydrophilic $(\mathrm{HI})$ and hydrophobic $(\mathrm{HO})$ microphase separation, the APCNs showed swelling in both water and organic solvents with different optical properties. The method provides an interesting route for making functional biodegradable APCNs using radical chemistry in the future by choosing appropriate vinyl comonomers.
\end{abstract}

\section{Introduction}

Amphiphilic conetworks (APCNs), composed of covalently linked hydrophilic and hydrophobic (HI/HO) chain segments, have the capability of swelling in both water and organic solvents. ${ }^{1-5}$ Owing to the unique structures and properties, APCNs were developed for various applications. ${ }^{6-15}$ One of the applications of APCNs is in the stabilization and enhancement of enzymatic activity in organic solvents. ${ }^{14}$

The most common method of making APCNs, in fact one of the first examples, was using radical copolymerization of polymerizable telechelics (low molar mass polymers with polymerizable chain-ends) with a suitable comonomer. ${ }^{16-18}$ Other methods used for the formation of APCNs were click chemistry, ${ }^{5}$ thiol-ene reaction, ${ }^{19}$ Diels-Alder reaction ${ }^{20}$ etc.

Biodegradable APCNs would be highly interesting for many biomedical applications and have also been made using photo, thermal conventional/controlled radical polymerization

Macromolecular Chemistry II and Bayreuth Center for Colloids and Interfaces, University of Bayreuth, Universitätsstraße 30, 95440 Bayreuth, Germany. E-mail: agarwal@uni-bayreuth.de

$\dagger$ Electronic supplementary information (ESI) available: Homopolymerization and characterization of VCP and reactivity ratio calculations. See DOI: 10.1039/ c5py00962f of $\alpha, \omega$-acrylate chain-end functionalized common biodegradable polymers such as poly(L-lactide), polyglycolide and poly(e-caprolactone) (PCL) with comonomers like 2-hydroxyethyl methacrylate and $N, N$-dimethylaminoethyl methacrylate. ${ }^{21-23}$ In all these examples aliphatic polyesters made by metal catalyzed ring-opening polymerization (ROP) of corresponding cyclic esters were used as degradable hydrophobic segment. ${ }^{24}$ Both chain-ends were modified with polymerizable double bonds, i.e. acrylate units, to make them suitable as cross-linker in radical copolymerization with hydrophilic comonomers in a second step. In addition, azide-alkyne coupling of diazide chain-end functionalised ABA triblock copolymers of PCL and PEO with tetrakis(2-propynyloxymethyl) methane (TMOP) was also applied. ${ }^{5}$

Polyesters, in general, can also be prepared by radical ringopening polymerization (RROP) of cyclic ketene acetals (CKAs). This method provides opportunities of making functional polyesters in a simple but versatile way by copolymerization of CKAs with a large variety of vinyl comonomers available. ${ }^{25-38}$ The formation of polyester during copolymerization depends upon the reaction conditions and comonomer type as CKAs can also undergo vinyl polymerization without isomerization leading to polyacetals with ring-retained structures.

Vinylcyclopropane (VCP) and its derivatives are interesting vinyl monomers undergoing radical ring-opening polymerization for the formation of polymers with unsaturated units in 
the backbone ${ }^{39-47}$ and have been intensively studied for dental applications as low volume shrinkage monomers (Scheme 1A). The copolymerization of VCP with CKAs could provide new polymers with cross-linkable unsaturated units and biodegradable ester linkages randomly distributed on the polymer backbone (Scheme 1C), which could be useful for making APCNs. Unsaturated biodegradable amphiphilic hydrogels made by condensation polymerization of diol functionalised PCL and poly(ethylene glycol) with diacid functionalised poly(propylene fumarate), followed by cross-linking with polyacrylamide are known in the literature with main focus on swellability in water. ${ }^{48,49}$

We highlight the formation of APCNs, in which the hydrophobic part is made by radical ring-opening copolymerization of vinylcyclopropane (VCP) and 2-methylene-4-phenyl-1,3dioxolane (MPDO), followed by cross-linking with a hydrophilic macromonomer oligo(ethylene glycol) methacrylate (OEGMA, $M_{\mathrm{n}} \sim 500$ ). The copolymerization of VCP and MPDO provides an unsaturated polyester with random distribution of carbon-carbon double bonds and ester units, as characterized by reactivity ratio determination. This is a new method of making unsaturated polyesters (UPs) by radical polymerization with the advantage of easy and versatile introduction of additional functional groups simply by choosing appropriate vinyl comonomers. The state-of-the art method of making UPs is by condensation polymerization using high temperatures that restricts the use of many functional monomers. The APCNs were characterized by swelling studies in water and DMF, and the enzymatic degradability of APCNs was studied using Lipase from Pseudomonas cepacia in $\mathrm{pH}=7$ PBS buffer solution. The unique swelling property and biodegradability of the prepared APCNs suggests the potential application in the biomaterial field.
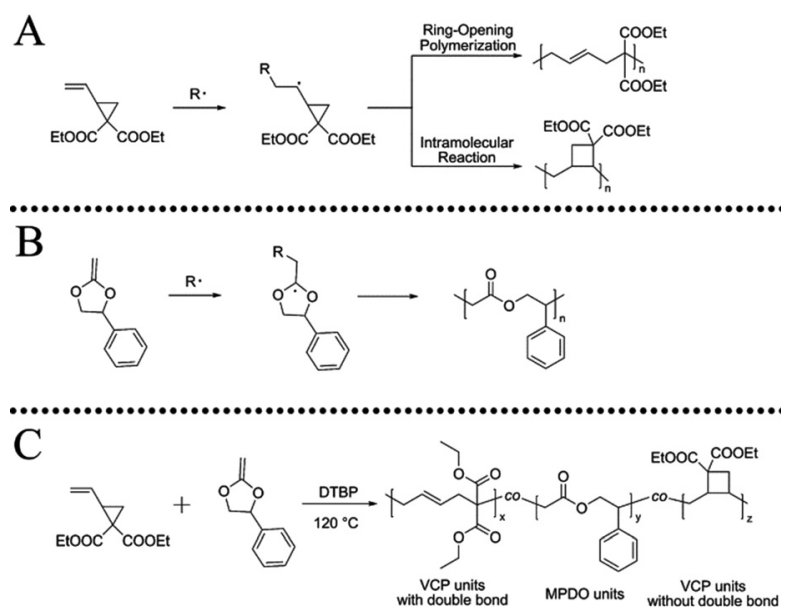

Scheme 1 Schematic process of radical ring-opening polymerization (RROP) of (A) vinylcyclopropane (VCP), ${ }^{39}$ (B) 2-methylene-4-phenyl-1,3dioxolane (MPDO), ${ }^{50}$ and (C) VCP and MPDO.

\section{Experimental section}

\section{Materials}

1-Phenyl-1,2-ethanediol (Aldrich), potassium tert-butoxide (Acros), $p$-toluenesulfonic acid (Aldrich), 1,4-dibromo-2-butene (Aldrich), diethyl malonate (Aldrich), sodium (Aldrich), di-tertbutyl peroxide (DTBP, Aldrich) and Lipase (from Pseudomonas cepacia, $\geq 30 \mathrm{U} \mathrm{mg}^{-1}$, Aldrich) were used as received. All solvents were distilled before use. Oligo(ethylene glycol) methacrylate (OEGMA, $M_{\mathrm{n}} \sim 500$, Aldrich) was passed through a basic alumina column to remove the inhibitor.

2-Methylene-4-phenyl-1,3-dioxolane (MPDO) was synthesized using the literature method of W. J. Bailey et al. ${ }^{50}$ with some modifications. 2-Vinylcyclopropane-1,1-dicarboxylate (VCP) was synthesized using the literature method of T. Endo et al. ${ }^{39}$

\section{Instrumentation}

${ }^{1} \mathrm{H}(300 \mathrm{MHz}),{ }^{13} \mathrm{C}(75 \mathrm{MHz})$ NMR spectra were recorded on a Bruker Ultrashied-300 spectrometer in $\mathrm{CDCl}_{3}$, using tetramethylsilane (TMS) as an internal standard. Molecular weights and molar-mass dispersities $\left(D_{M}\right)$ of the polymers were determined by gel permeation chromatography (GPC) with a Knauer system equipped with 4 PSS-SDV gel columns (particle size $=5 \mu \mathrm{m}$ ) with pore sizes ranging from $10^{2}$ to $10^{5} \AA$ (PSS, Mainz, Germany) together with a differential refractive index detector (RI-101 from Shodex). THF (HPLC grade) was used as

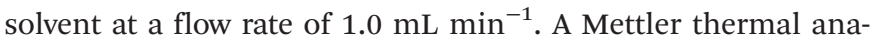
lyzer with 851 TG and 821 DSC modules was used for the thermal characterization of copolymers. Thermal stability was determined by recording TGA traces at a heating rate of $10 \mathrm{~K}$ $\mathrm{min}^{-1}$ in nitrogen atmosphere (flow rate $=50 \mathrm{ml} \mathrm{min}^{-1}$ ). DSC scans were recorded in nitrogen atmosphere (flow rate $=80 \mathrm{ml}$ $\mathrm{min}^{-1}$ ) at a scanning rate of $10 \mathrm{~K} \mathrm{~min}^{-1}$. A sample mass of 10 $\pm 1 \mathrm{mg}$ was used in both DSC and TGA analysis.

\section{Copolymerization of MPDO and VCP under free radical condition}

The mixture of MPDO and VCP with different molar ratios and di-tert-butyl peroxide as initiator were added into a $10 \mathrm{~mL}$ Schlenk tube equipped with a magnetic stir bar under argon. After degassing by freeze-vacuum-thaw cycles three times, the tubes were sealed under argon, and then placed in a preheated oil bath at $120{ }^{\circ} \mathrm{C}$ for $48 \mathrm{~h}$ while stirring. Subsequently, the tubes were opened and the reaction mixture was poured into methanol while stirring to cause polymer precipitation. Finally, the purified polymer was dried under vacuum at $60{ }^{\circ} \mathrm{C}$ for $48 \mathrm{~h}$. Copolymerization of MPDO and VCP for reactivity ratios calculation was carried out with various feed ratios at $120{ }^{\circ} \mathrm{C}$ and stopped at low conversion. The reactivity ratios were calculated using Kelen-Tüdõs method. ${ }^{51}$ Details are given in the ESI. $\dagger$

\section{APCN preparation using VCP-MPDO copolymers and OEGMA under free radical condition}

VCP-MPDO copolymer, OEGMA and DTBP were dissolved in $0.5 \mathrm{~mL}$ dioxane at a molar ratio of carbon-carbon double 
bonds : OEGMA : DTBP $=1: 25: 1$. After degassing with argon for $1 \mathrm{~h}$, the reaction mixture was placed in a preheated oil bath at $140{ }^{\circ} \mathrm{C}$ for $24 \mathrm{~h}$ without stirring. After the polymerization, the resulting gel was extracted with chloroform overnight to remove the unreacted VCP-MPDO copolymer and linear POEGMA. Finally, the purified APCNs were dried in vacuum at $60{ }^{\circ} \mathrm{C}$ for $24 \mathrm{~h}$.

\section{In vitro degradation studies of APCNs}

In vitro degradation studies of APCNs were carried out by placing APCNs in $\mathrm{pH}=7$ PBS buffer solution with the enzyme concentration of $15 \mathrm{U} \mathrm{mL}^{-1}$ (Lipase from Pseudomonas cepacia) at $37{ }^{\circ} \mathrm{C}$. The degradation medium was replaced every $24 \mathrm{~h}$. The remaining mass of APCNs was recorded after freeze drying at different degradation time.

\section{Results and discussion}

\section{Copolymerization of VCP with MPDO}

Various copolymers of VCP with MPDO were prepared by changing the molar ratio of the two monomers in the initial feed (Scheme 1, Table 1).

After purification, the resulting copolymers were obtained as white solids. The copolymer structure was analyzed by NMR spectroscopy (Fig. 1). According to the NMR spectra of PVCP (please see ESI, Fig. S1 $^{\text {) }}$ and $\mathrm{PMPDO}^{50}$ homopolymer, the characteristic peaks of VCP and MPDO units were confirmed and marked in Fig. 1. In the ${ }^{13} \mathrm{C}-\mathrm{NMR}$ spectrum (Fig. 1B), the absence of peaks between $\delta=90-110$ ppm confirms that all MPDO units were copolymerized as ring-opened structure providing ester units in the polymer backbone (structure 3 in Fig. 1). In the ${ }^{1} \mathrm{H}-\mathrm{NMR}$ spectrum (Fig. 1A), the broad peak $\mathrm{c}$ at $\delta=4.7-5.3 \mathrm{ppm}$ originates from the carbon-carbon double bond $-\mathrm{CH}=\mathrm{CH}$ - of VCP units with ring-opened structure (structure 1 in Fig. 1), the peak a at $\delta=0.9-1.1 \mathrm{ppm}$ from the $\mathrm{CH}_{3} \mathrm{CH}_{2} \mathrm{O}$ - group of VCP units with ring-opened and also ringclosed structure (structures $\mathbf{1}$ and 2 in Fig. 1) and peak b,i between $\delta=3.7-4.5 \mathrm{ppm}$ were assigned to the $-\mathrm{CH}_{2}-\mathrm{CH}(\mathrm{Ph})-$ group of MPDO units and $\mathrm{CH}_{3} \mathrm{CH}_{2} \mathrm{O}-$ group of VCP units in the copolymer. Through comparing the areas of these 3 peaks, the VCP-MPDO copolymer composition was calculated.

The 2D HMBC NMR spectrum (Fig. 2) shows correlation of the proton peaks originating from d,e of VCP units (structure
1) at $2.4 \mathrm{ppm}$ with the aromatic carbon signals of MPDO units (structure 3) at $128 \mathrm{ppm}$, confirming covalent linkage between VCP and MPDO units in the copolymer. The compositions of VCP-MPDO copolymers with different monomer ratio in feed are summarized in Table 1. An increase of VCP in the initial feed led to a higher VCP content in the VCP-MPDO copolymer and slightly increased amount of ring-retained
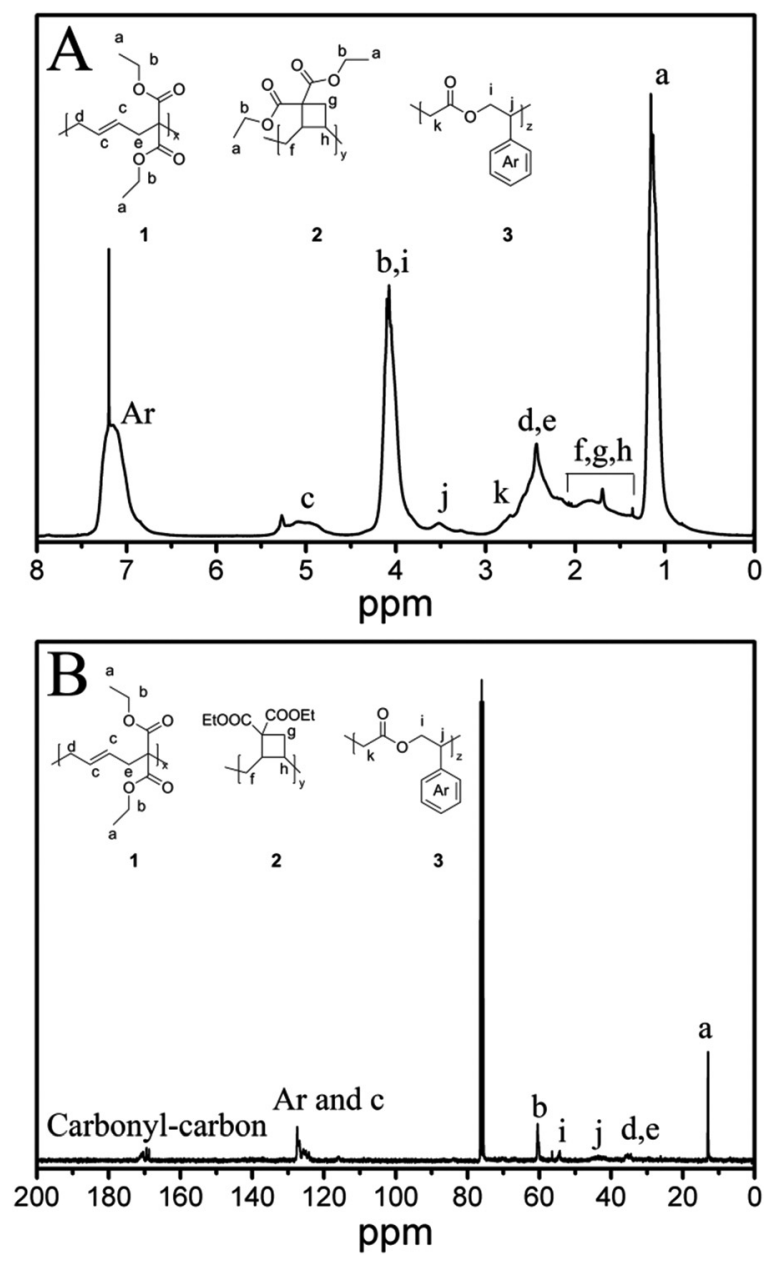

Fig. 1 NMR-spectra of VCP-MPDO copolymer (entry 1 in Table 1). A: ${ }^{1} \mathrm{H}-\mathrm{NMR}$ spectrum; B: ${ }^{13} \mathrm{C}-\mathrm{NMR}$ spectrum. Structure 1 : VCP unit with ring-opened structure in copolymer; structure 2: VCP unit with ringretained structure in copolymer; structure 3: MPDO unit in copolymer.

Table 1 Copolymerization data for VCP-MPDO copolymers

\begin{tabular}{|c|c|c|c|c|c|c|c|c|}
\hline Entry $^{a}$ & \multicolumn{2}{|c|}{ Feed ratio $(\mathrm{mol} \%)$} & Yield \% & $M_{\mathrm{n}}^{b}\left(\mathrm{~g} \mathrm{~mol}^{-1}\right)$ & $D_{M}^{b}$ & \multicolumn{3}{|c|}{ Copolymer composition $^{c}(\mathrm{~mol} \%)$} \\
\hline 1 & 30 & 70 & 33 & $5.4 \times 10^{3}$ & 1.4 & 25 & 20 & 55 \\
\hline 2 & 50 & 50 & 43 & $8.3 \times 10^{3}$ & 1.4 & 31 & 28 & 41 \\
\hline 3 & 70 & 30 & 46 & $1.2 \times 10^{4}$ & 1.8 & 29 & 35 & 36 \\
\hline
\end{tabular}

${ }^{a}$ Initiator: DTBP ( $1 \mathrm{wt} \%$ of monomer); reaction temperature: $120{ }^{\circ} \mathrm{C}$; reaction time: $48 \mathrm{~h} .{ }^{b}$ Determined by THF-GPC with RI detector; PSstandards used for calibration (Fig. 3). ${ }^{c}$ Determined by ${ }^{1} \mathrm{H}-\mathrm{NMR}$ spectra of resulting VCP-MPDO copolymers (Fig. 1A). 


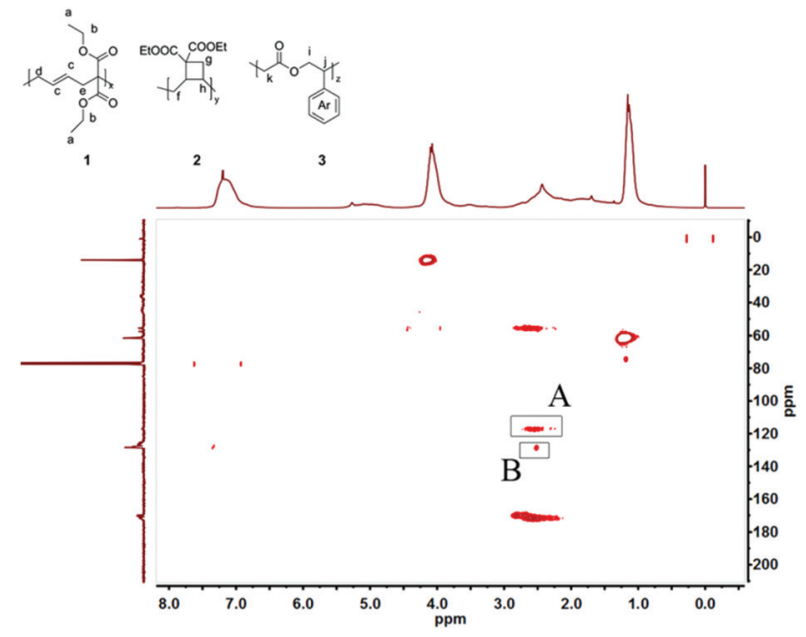

Fig. 2 HMBC spectrum of VCP-MPDO copolymer (entry 1 in Table 1). Cross-peak A: Coupling between group d,e of VCP unit with ringopened structure (structure 1) and carbon-carbon double bond $c$ of VCP unit with ring-opened structure (structure 1); cross-peak B: Coupling between group d,e of VCP unit with ring-opened structure (structure 1) and phenyl group of MPDO unit (structure 3 ).

cyclobutane units. The cyclobutane units were formed by the addition of a newly formed radical during propagation via ring-opening of VCP to the double bond of the same unit in the polymer main chain i.e. intramolecular isomerization, a very well-known reaction during ring-opening polymerization of VCP. ${ }^{52}$ It is a competitive reaction with the reaction of ringopened propagating VCP radical with a new VCP monomer/ MPDO and increases slightly ( $45 \%$ to $55 \%$ ) with the VCP content in the reaction mixture (Table 1) when all other parameters such as amount and type of the initiator and temperature of polymerization remained the same. The change in the amount of ring-retained structure with feed composition is not very drastic. In our previous work about homopolymerization of VCP using DTBP initiator at $120^{\circ} \mathrm{C}$ the ratio of ring-opened and ring-retained structures were about $50: 50 .^{52}$

The number-average molecular weights of the resulting VCP-MPDO copolymers were determined by THF-GPC applying a polystyrene calibration and ranged from $5.4 \times 10^{3}$ to $1.2 \times$ $10^{4} \mathrm{~g} \mathrm{~mol}^{-1}$ (Table 1). The corresponding GPC-traces show unimodal molecular weight distributions for all copolymers (Fig. 3). An increase of VCP in the initial feed led to a higher molar mass of the resulting copolymer.

The reactivity ratios of the two monomers were calculated using the Kelen-Tüdõs method. ${ }^{51}$ To that end, a series of VCP-MPDO copolymers with low yields $(<5 \%)$ were prepared. The composition of the resulting polymers was determined using ${ }^{1} \mathrm{H}$-NMR technique as described above. A detailed discussion on the determination of the reactivity ratios can be found in the ESI (Tables S1, S2 and Fig. S3, S4 $\dagger$ ). From the corresponding Kelen-Tüdõs plot (Fig. S3†) the reactivity ratios of VCP and MPDO were determined to $r_{\mathrm{VCP}}=0.23 \pm 0.08$ and $r_{\mathrm{MPDO}}=0.18 \pm 0.02$. There are no big differences between the

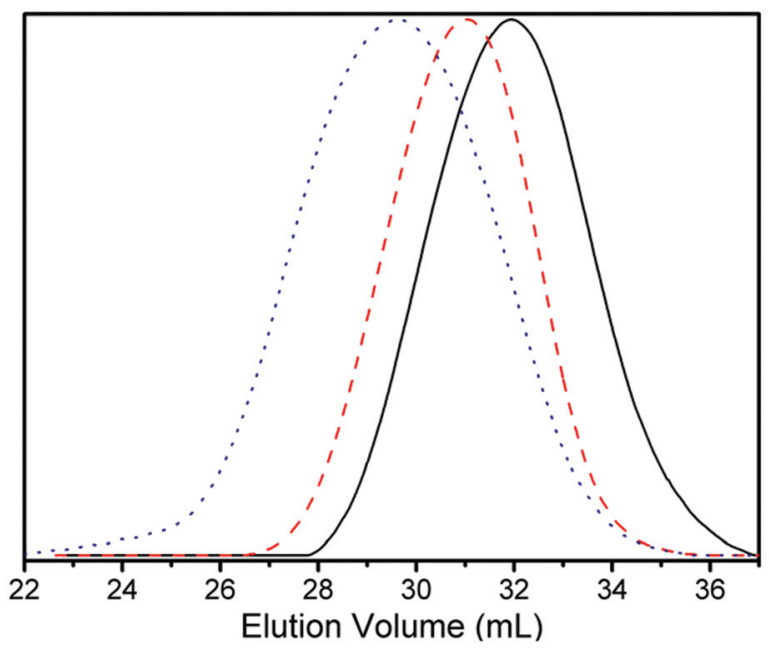

Fig. 3 THF-GPC traces of VCP-MPDO copolymers with different comonomer ratios in feed. Reaction temperature: $120^{\circ} \mathrm{C}$, reaction time: 48 h. Composition in feed: black-solid line: VCP : MPDO = 30:70; redbroken line: VCP : MPDO = 50:50; blue-dotted line: VCP : MPDO = $70: 30$.

reactivity ratios of VCP and MPDO and both values are below 1. Consequently, depending on the monomer unit at the active chain end, i.e., VCP or MPDO, the incorporation of the respective other comonomer, i.e., MPDO or VCP, is slightly preferred (copolymerization diagram in Fig. S4†). This suggests a nearly random distribution of MPDO and VCP units in the copolymer.

Thermal characterization of VCP-MPDO copolymers was carried out using TGA and DSC techniques. The glass transition and decomposition temperatures of the copolymers are listed in Table 2.

The copolymers show a high thermal stability ( $T_{\max }$ : temperature at which rate of decomposition was maximum = $400-410^{\circ} \mathrm{C}$ ) with single step decomposition (please see Fig. S5 in ESI $\uparrow$ ). Single glass transition was obtained for copolymers with different comonomer ratios (please see Fig. S6 in ESI†), reconfirming the nearly random incorporation of MPDO and VCP in the copolymer chains.

Table 2 Thermal properties of VCP-MPDO copolymers

\begin{tabular}{|c|c|c|c|c|c|}
\hline \multirow[b]{2}{*}{ Entry $^{a}$} & \multicolumn{3}{|c|}{ Copolymer composition $^{b}(\mathrm{~mol} \%)$} & \multirow[b]{2}{*}{$\begin{array}{l}T_{\mathrm{g}}^{c} \\
\left({ }^{\circ} \mathrm{C}\right)\end{array}$} & \multirow[b]{2}{*}{$\begin{array}{l}\text { Dec. } \\
\text { temp. }{ }^{d}\left({ }^{\circ} \mathrm{C}\right)\end{array}$} \\
\hline & $\begin{array}{l}\text { VCP } \\
\text { (ring-opened) }\end{array}$ & $\begin{array}{l}\text { VCP } \\
\text { (ring-retained) }\end{array}$ & MPDO & & \\
\hline 1 & 25 & 20 & 55 & 45 & 402 \\
\hline 2 & 31 & 28 & 41 & 43 & 410 \\
\hline 3 & 29 & 35 & 36 & 49 & 410 \\
\hline
\end{tabular}

${ }^{a}$ Initiator: DTBP ( $1 \mathrm{wt} \%$ of monomer); reaction temperature: $120{ }^{\circ} \mathrm{C}$; reaction time: $48 \mathrm{~h}$; same as entries $1-3$ in Table $1 .{ }^{b}$ Determined by ${ }^{1}$ H-NMR spectra (Fig. 1A). ${ }^{c}$ Determined by DSC (please see Fig. S6 in ESI). ${ }^{d}$ Determined by TGA (please see Fig. S5 in ESI). 


\section{Synthesis of biodegradable amphiphilic conetworks using VCP-MPDO copolymers}

Based on the cross-linkable carbon-carbon double bonds and the almost random VCP-MPDO combination on the copolymer backbone (random distribution of ester units), the VCP-MPDO copolymers have the potential to be used for the preparation of biodegradable amphiphilic conetworks (APCNs). As shown in Scheme 2, APCNs were prepared from a reaction mixture of VCP-MPDO copolymer, OEGMA and DTBP in dioxane with a molar ratio of carbon-carbon double bonds : OEGMA : DTBP = $1: 25: 1$ at $140{ }^{\circ} \mathrm{C}$. After $24 \mathrm{~h}$ reaction, colorless cross-linked gels with very high gel fractions were obtained. The gel fraction was determined by calculating the ratio of the gel dry mass to polymer precursor mass (Table 3 ). The FT-IR showed the presence of characteristic peaks of both VPC-MPDO copolymer and POEGMA segments in the APCNs (please see ESI Fig. S2 $\dagger$ ).

\section{Characterization of biodegradable APCNs}

The swelling property is one of the most important properties of APCNs and it was studied by immersing dry gels in different solvents. The swelling ratio was calculated using the following

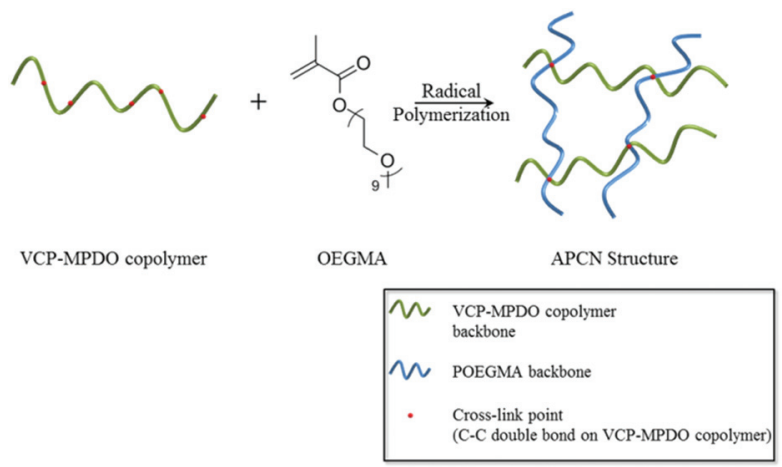

Scheme 2 Preparation of biodegradable amphiphilic conetworks. OEGMA = oligo(ethylene glycol) methacrylate, $M_{\mathrm{n}} \sim 500 \mathrm{~g} \mathrm{~mol}^{-1}$. Ditert-butyl peroxide was used as initiator and reaction temperature was at $140{ }^{\circ} \mathrm{C}$.

Table 3 Physical properties of APCNs prepared using VCP-MPDO copolymers $^{a}$

\begin{tabular}{llll}
\hline & & \multicolumn{2}{l}{$\begin{array}{l}\text { Weight swelling ratio (w/w) } \\
\text { after equilibration }(\%)\end{array}$} \\
\cline { 3 - 4 } Sample & $\begin{array}{l}\text { Gel fraction } \\
(\%)\end{array}$ & In water & In DMF \\
\hline Gel 1 $^{b}$ & 79 & 1130 & 1230 \\
Gel 2 $^{c}$ & 91 & 1030 & 1160 \\
Gel 3 & 93 & 1070 & 1150
\end{tabular}

${ }^{a}$ The OEGMA: VCP-MPDO (feed molar ratio) was $6.25: 1,7.75: 1$ and $7.25: 1$ for gels 1,2 and 3 , respectively. ${ }^{b}$ APCNs Gel 1 : prepared by VCP-MPDO copolymer of entry 1 in Table $1 .{ }^{c}$ APCNs Gel 2: prepared by VCP-MPDO copolymer of entry 2 in Table $1 .{ }^{d}$ APCNs Gel 3 : prepared by VCP-MPDO copolymer of entry 3 in Table 1. equation and averaged for 3 samples:

Weight swelling ratio $=\left[\left(\right.\right.$ weight $_{\text {swollen gel }} /$ weight $\left.\left._{\text {dry gel }}\right)-1\right]$

$$
\times 100 \%(\mathrm{w} / \mathrm{w})
$$

Because of the co-existence of hydrophilic (HI) and hydrophobic (HO) structures in the copolymer network, the APCNs show different swelling properties in various solvents. The swelling properties of APCNs in water and DMF are shown in Fig. 4 and listed in Table 3.

The gels showed equilibration in water and also DMF in approximately $8 \mathrm{~h}$. DMF is a good solvent for both the hydrophilic and hydrophobic phases in the resulting APCNs and results in an extension of all polymer chains in the networks. However, water is a selective solvent only for the hydrophilic phase and only the poly[oligo(ethylene glycol) methacrylate] (POEGMA) segments extend in water. Due to the lowest content of VCP units with carbon-carbon double bond in the VCP-MPDO copolymer for network preparation, Gel 1 has the lowest concentration of cross-linking points in the network and hence showed the maximum swelling ratio of $1130 \%$ in water (Fig. 4B) and $1230 \%$ in DMF (Fig. 4A). It was larger than Gel 2 (1030\% in water and 1160\% in DMF) and Gel $3(1070 \%$ in water and $1150 \%$ in DMF). The swelling ratios of all APCNs
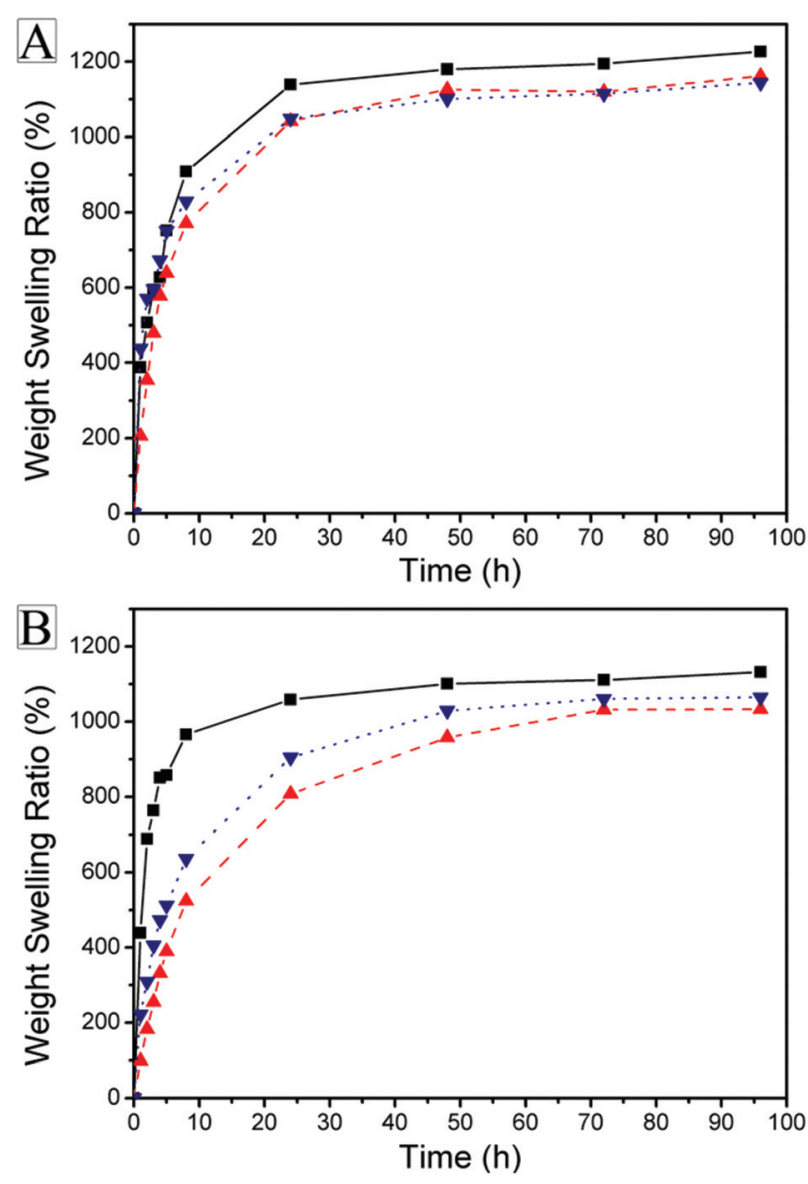

Fig. 4 Weight swelling ratio of APCNs (black: Gel 1, red: Gel 2, blue: Gel 3) in (A) DMF and (B) water. 
in water were smaller than in DMF. All APCNs showed a high transparency in DMF (Fig. 5 top) due to the extension of both hydrophobic and hydrophilic parts. Because of the phase separation between the hydrophilic (POEGMA chains) and hydrophobic (VCP-MPDO copolymer) segments, the APCNs appeared opaque in water (Fig. 5 bottom).

Due to the influence of polymer crystallinity to the drug permeation and biodegradability of the whole network in the aim of biomedical application, ${ }^{53}$ the thermal properties of APCNs were studied through DSC technique (Fig. 6). The APCNs showed a low melting temperature around $-3{ }^{\circ} \mathrm{C}$ due to oligo(ethylene glycol) side-chains. The glass transition temperature of the VCP-MPDO copolymer segments in the conetwork was observed at $45^{\circ} \mathrm{C}$ and $T_{\mathrm{g}}$ of POEGMA backbone at $85{ }^{\circ} \mathrm{C}$, respectively. Due to the higher glass transition temperature of the hydrophobic segments in the conetwork, the APCNs could keep their shape at room temperature.

The degradation behavior of APCNs was studied by placing APCNs in $\mathrm{pH}=7$ PBS buffer solution with the enzyme concentration of $15 \mathrm{U} \mathrm{mL}^{-1}$ at $37{ }^{\circ} \mathrm{C}$ (Lipase from Pseudomonas cepacia) (Fig. 7). The degradability of cross-linked APCNs was realized through cleavage of VCP-MPDO copolymer segments, which act as cross-linking chains in the APCNs. The weight loss noted might be due to the release of POEGMA chains

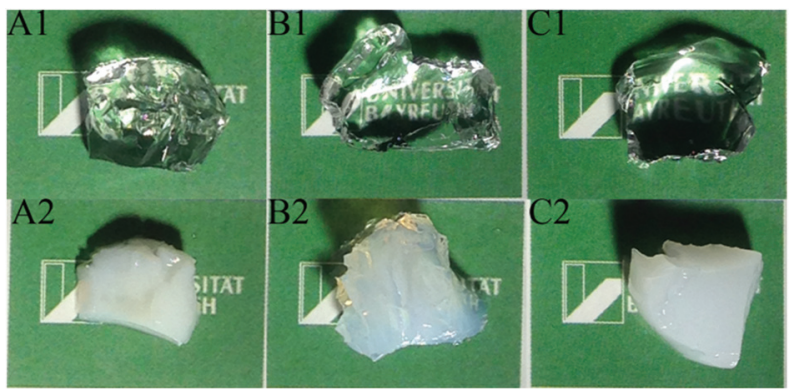

Fig. 5 Photographs of APCNs swollen in different solvents. A1: Gel 1 in DMF; A2: Gel 1 in $\mathrm{H}_{2} \mathrm{O}$; B1: Gel 2 in DMF; B2: Gel 2 in $\mathrm{H}_{2} \mathrm{O}$; $\mathrm{C} 1$ : Gel 3 in DMF; C2: Gel 3 in $\mathrm{H}_{2} \mathrm{O}$.

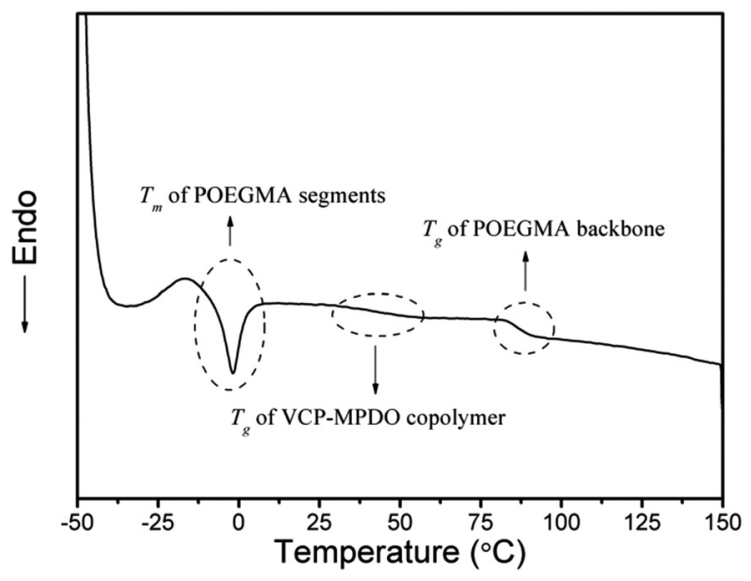

Fig. 6 DSC heating trace of purified APCNs, Gel 3 as an example.

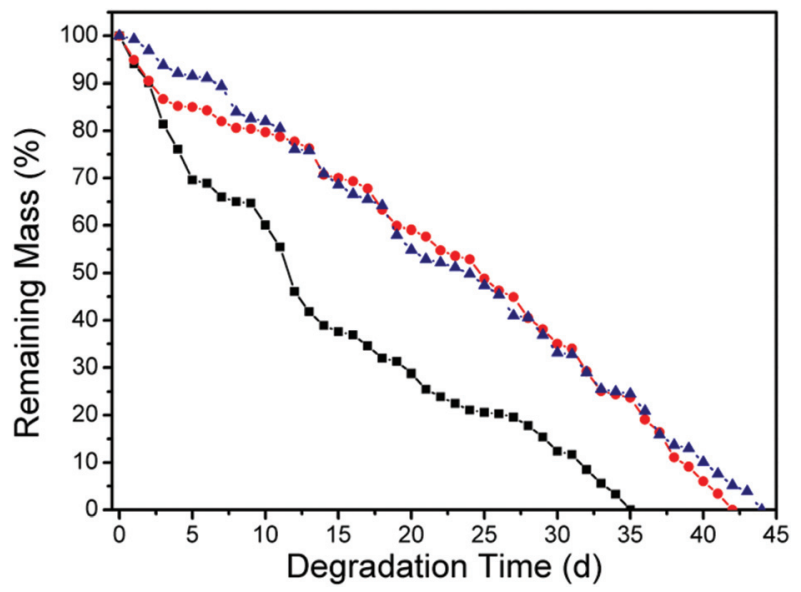

Fig. 7 Mass loss of APCNs against enzyme in $\mathrm{pH}=7$ PBS buffer solution in dependence of degradation time. Black: Gel 1; red: Gel 2; navy: Gel 3.

or OEGMA fragments or a combination of both after enzymatic degradation of ester units from VCP-MPDO and ester units of POEGMA linking OEGMA to the polymer backbone. The complete degradability of the present APCNs is not possible due to the $\mathrm{C}-\mathrm{C}$ backbone of POEGMA. Due to the highest content of ester bonds from MPDO-units and the lowest content of carbon-carbon double bonds as cross-linking points from ring-opened VCP-units in the conetwork, Gel 1 exhibited the fastest decomposition rate and was decomposed in $35 \mathrm{~d}$ in the presence of Lipase from Pseudomonas cepacia.

\section{Conclusions}

Cross-linkable unsaturated polyesters were prepared by radical ring-opening copolymerization of VCP and MPDO. The unsaturated and ester units were provided by ring-opening of VCP and cyclic ketene acetal (MPDO), respectively, and were distributed almost randomly along the copolymer backbone. The VCP-MPDO copolymers were used as hydrophobic (HO) precursors for the formation of amphiphilic conetworks (APCNs) via copolymerization with OEGMA, forming the hydrophilic (HI) part. Through the free radical polymerization of OEGMA in the presence of VCP-MPDO copolymer, the APCNs were successfully produced. The concentration of the cross-linking points and hence the swelling property of APCNs in DMF and water depend on the amount of double bonds in the hydrophobic precursor. The APCNs provided unique swelling property with excellent enzymatic degradability. The method provides a simple and versatile route for making functional biodegradable APCNs using radical chemistry in the future.

\section{Acknowledgements}

Authors would like to thank Deutsche Forschungsgemeinschaft (DFG) for the financial support. The work was carried out in the frame of SFB 840 . 


\section{References}

1 C. S. Patrickios and T. K. Georgiou, Curr. Opin. Colloid Interface Sci., 2003, 8, 76-85.

2 G. Erdodi and J. P. Kennedy, Prog. Polym. Sci., 2006, 31, 1-18.

3 L. Mespouille, J. L. Hedrick and P. Dubois, Soft Matter, 2009, 5, 4878-4892.

4 M. Rikkou-Kalourkoti, E. Loizou, L. Porcar, K. Matyjaszewski and C. S. Patrickios, Polym. Chem., 2012, 3, 105-116.

5 Y. Yuan, A.-K. Zhang, J. Ling, L.-H. Yin, Y. Chen and G.-D. Fu, Soft Matter, 2013, 9, 6309-6318.

6 L. Bromberg, M. Temchenko and T. A. Hatton, Langmuir, 2002, 18, 4944-4952.

7 J. Zednik, R. Riva, P. Lussis, C. Jérôme, R. Jérôme and P. Lecomte, Polymer, 2008, 49, 697-702.

8 C. Lin and I. Gitsov, Macromolecules, 2010, 43, 1001710030.

9 J. P. Kennedy, Macromol. Symp., 2001, 175, 127-132.

10 I. Gitsov and C. Zhu, J. Am. Chem. Soc., 2003, 125, 1122811234.

11 I. Gitsov and C. Zhu, Macromolecules, 2002, 35, 8418-8427.

12 R. Haigh, N. Fullwood and S. Rimmer, Biomaterials, 2002, 23, 3509-3516.

13 S. Rimmer, M. J. German, J. Maughan, Y. Sun, N. Fullwood, J. Ebdon and S. MacNeil, Biomaterials, 2005, 26, 2219-2230.

14 N. Bruns and J. C. Tiller, Nano Lett., 2004, 5, 45-48.

15 G. Savin, N. Bruns, Y. Thomann and J. C. Tiller, Macromolecules, 2005, 38, 7536-7539.

16 D. Chen, J. P. Kennedy and A. J. Allen, J. Macromol. Sci., Part A: Pure Appl. Chem., 1988, 25, 389-401.

17 E. Themistou and C. S. Patrickios, Macromolecules, 2004, 37, 6734-6743.

18 E. Loizou, A. I. Triftaridou, T. K. Georgiou, M. Vamvakaki and C. S. Patrickios, Biomacromolecules, 2003, 4, 11501160.

19 C. N. Walker, K. C. Bryson, R. C. Hayward and G. N. Tew, ACS Nano, 2014, 8, 12376-12385.

20 M. Delerba, J. R. Ebdon and S. Rimmer, Macromol. Rapid Commun., 1997, 18, 723-728.

21 A. S. Sawhney, C. P. Pathak and J. A. Hubbell, Macromolecules, 1993, 26, 581-587.

22 I. Barakat, P. Dubois, R. Jérôme, P. Teyssié and E. Goethals, J. Polym. Sci., Part A: Polym. Chem., 1994, 32, 2099-2110.

23 I. Barakat, P. Dubois, C. Grandfils and R. Jérôme, J. Polym. Sci., Part A: Polym. Chem., 1999, 37, 2401-2411.

24 T. Chen, T. Cai, Q. Jin and J. Ji, e-Polymers, 2015, 15, 3-13.

25 S. Agarwal, Polym. Chem., 2010, 1, 953-964.

26 W. J. Bailey, Z. Ni and S.-R. Wu, J. Polym. Sci., Polym. Chem. Ed., 1982, 20, 3021-3030.

27 J. Bailey, J. L. Chou, P. Z. Feng, V. Kuruganti and L. L. Zhou, Acta Polym., 1988, 39, 335-341.

28 W. J. Bailey, Z. Ni and S. R. Wu, Macromolecules, 1982, 15, 711-714.
29 L. Ren, C. Speyerer and S. Agarwal, Macromolecules, 2007, 40, 7834-7841.

30 H. Wickel, S. Agarwal and A. Greiner, Macromolecules, 2003, 36, 2397-2403.

31 J.-F. Lutz, J. Andrieu, S. Üzgün, C. Rudolph and S. Agarwal, Macromolecules, 2007, 40, 8540-8543.

32 N. Xiao, H. Liang and J. Lu, Soft Matter, 2011, 7, 1083410840.

33 G. G. Hedir, C. A. Bell, N. S. Ieong, E. Chapman, I. R. Collins, R. K. O'Reilly and A. P. Dove, Macromolecules, 2014, 47, 2847-2852.

34 B. Ochiai and T. Endo, J. Polym. Sci., Part A: Polym. Chem., 2007, 45, 2827-2834.

35 A. Tardy, V. Delplace, D. Siri, C. Lefay, S. Harrisson, B. de Fatima Albergaria Pereira, L. Charles, D. Gigmes, J. Nicolas and Y. Guillaneuf, Polym. Chem., 2013, 4, 4776-4787.

36 Y. Zhang, M. Zheng, T. Kissel and S. Agarwal, Biomacromolecules, 2011, 13, 313-322.

37 L. Ren and S. Agarwal, Macromol. Chem. Phys., 2007, 208, 245-253.

38 Y. Shi and S. Agarwal, e-Polymers, 2015, 15, 217-226.

39 F. Sanda, T. Takata and T. Endo, Macromolecules, 1993, 26, 1818-1824.

40 F. Sanda and T. Endo, J. Polym. Sci., Part A: Polym. Chem., 2001, 39, 265-276.

41 A. de Meijere, V. Bagutski, F. Zeuner, U. K. Fischer, V. Rheinberger and N. Moszner, Eur. J. Org. Chem., 2004, 3669-3678.

42 T. Hirano, A. Tabuchi, M. Seno and T. Sato, Macromolecules, 2001, 34, 4737-4741.

43 V. Delplace, S. Harrisson, A. Tardy, D. Gigmes, Y. Guillaneuf and J. Nicolas, Macromol. Rapid Commun., 2014, 35, 484-491.

44 S. Ata, D. Mal and N. K. Singha, RSC Adv., 2013, 3, 1448614494.

45 D. J. Siegwart, J. K. Oh and K. Matyjaszewski, Prog. Polym. Sci., 2012, 37, 18-37.

46 D. H. Seuyep N, D. Szopinski, G. A. Luinstra and P. Theato, Polym. Chem., 2014, 5, 5823-5828.

47 D. H. Seuyep N, G. A. Luinstra and P. Theato, Polym. Chem., 2013, 4, 2724-2730.

48 E. Behravesh, S. Jo, K. Zygourakis and A. G. Mikos, Biomacromolecules, 2002, 3, 374-381.

49 L. Krishna and M. Jayabalan, J. Mater. Sci.: Mater. Med., 2009, 20, 115-122.

50 W. J. Bailey, S.-R. Wu and Z. Ni, Die Makromolekulare Chemie, 1982, 183, 1913-1920.

51 T. Kelen and F. Tüdõs, J. Macromol. Sci., Part A: Pure Appl. Chem., 1975, 9, 1-27.

52 P. P. Contreras, P. Tyagi and S. Agarwal, Polym. Chem., 2015, 6, 2297-2304.

53 W. Chen, F. Meng, R. Cheng and Z. Zhong, J. Controlled Release, 2010, 142, 40-46. 